\title{
The histological effects of a bio-energy water on degenerated adductor muscles in cultured juvenile abalone, Haliotis discus hannai
}

\author{
Asmat Ullah Shah ${ }^{1 *}$, Huh Min $\mathrm{Do}^{2}$, Bo Seong Kim² and Lawang Khan \\ Baloch $^{3}$ \\ 1. Fisheries and Coastal Development Department, Balochistan-Pakistan \\ 2. Department of Aquatic life Medicine, Pukyoung National University, Busan 608-737-Korea \\ 3. Department of Zoology/Fisheries University of Balochistan Quetta-Pakistan \\ *Corresponding author's email: asmatullah823@gmail.com \\ Citation \\ Asmat Ullah Shah, Huh Min Do, Bo Seong Kim and Lawang Khan Baloch. The histological effects of a bio-energy \\ water on degenerated adductor muscles in cultured juvenile abalone, Haliotis discus hannai. Pure and Applied \\ Biology. Vol. 9, Issue 1, pp478-490. http://dx.doi.org/10.19045/bspab.2020.90053
}

\begin{tabular}{llll}
\hline \hline Received: 06/08/2019 & Revised: 25/10/2019 & Accepted: 04/11/2019 & Online First: 19/11/2019 \\
\hline
\end{tabular}

\section{Abstract}

This study was conducted at Laboratory of Fish and Shellfish Pathology (LFSP), Department of Aquatic Life Medicine, Pukyong National University, Republic of Korea to examine the recovery of degenerated adductor muscles in juvenile abalone (Haliotis discus hannai) cultured in bioenergy water for four weeks. Juvenile abalones were fetched from an abalone farm; south Jeola Province Wando County, Republic of Korea which were divided into treatment and control groups. General sea water was used in control whereas bioenergy water was used in treatment groups. Five samples were collected randomly with $(n=8)$ individuals in each sampling. Juvenile abalones were dissected, fixed and refixed (in 10\%formalin). Adductor muscles were chopped, dehydrated for tissue processing (in 70-100\% ethyl alcohol) and embedded with paraffin wax $\left(58-62^{\circ} \mathrm{C}\right)$. Thin $(4 \mu \mathrm{m})$ ribbons of embedded tissues were obtained using rotatory microtome which were then stained with Haematoxylin and Eosin (H\&E method) and preceded for light microscopy finally. In the first sample (0 weeks), atrophy in adductor muscles was observed. In the second sample (one week after applying bioenergy water), muscle histology improved significantly. Muscle fiber histology recovered completely in the third sample (two weeks after applying bioenergy water). Lesions disappeared in fourth and fifth samples too (three and four weeks after applying bioenergy water). The adductor muscles recovered because of immunopotentiating characteristics of bioenergy water that sustained its normal structure. Results of this study suggest that bioenergy water can cure the degenerated adductor muscles of juvenile abalone. Bioenergy water could be used for culturing of fish/shell fish in future.

Keywords: Abalone; Adductor muscles; Bioenergy water; Haliotis discus hannai; Immunity; Lesion; Necrosis; Vacuolization

\section{Introduction}

Abalones (marine snails or gastropods) belong to phylum Mollusca, class Gastropoda, sub-class Orthogastropoda, order Vetigastropoda, super family Pleurotomarioidea, family Haliotidae and genus Haliotis [1, 2]. Haliotis generally means "sea ear" and refers to the ear-like 
shape of the abalone shell [3]. Abalones exist worldwide and are found in tropical, subtropical, warm temperate regions in both northern and southern hemispheres. The temperate zone contains large size abalones, whereas the small size abalones inhabit cold and tropical zones $[4,5]$.

At present, over 100 species of abalones have been reported to exist in the world oceans [6, 7]. Twenty-six (26) Haliotis species are commercially important and 16 species are being cultured in the world [8]. The optimum conditions for abalone, Haliotis discus hannai, culture are: water temperature $20^{\circ} \mathrm{C}$, salinity around $30 \mathrm{ppt}$, dissolved oxygen more than $4 \mathrm{ml} / \mathrm{L}$, $\mathrm{pH}$ around $8.0-8.3$. They are said to be sexually mature when, both, male and female abalone have a shell length of approximately $60 \mathrm{~mm}$ [9].

Abalone (Haliotis discus hannai) is successfully being cultured in Korea, China and Japan [10]. In culture system numerous water quality parameters inhibit growth rate and also affect immune system of abalone [11]. Temperature fluctuation changes the physiology and immune functions of ectothermic organisms, eventually causing mass mortalities $[12,13]$.

Any fluctuations in dissolved oxygen reduce the food intake that results in poor growth [14]. Salinity lower than 25-45 ppt causes death [15]. High ammonia concentration also causes stress, perturbs cellular biochemistry and physiology [16]. High stocking density decreases growth because of competition for shelter and food [17].

Adductor muscle in abalone is an important part of its body since it carries out body movements and helps the body attach on to a substratum. It also balances the body, helps in locomotion and food manipulation [18, 19].

Water plays a pivotal role in structure and function of biomolecules .Cellular structure, its cohesion and shape is maintained by water [20]. Any kind of water disruption within or outside the cell changes the structure of biomolecules which, then, leads to pathological diseases [21].

This study strongly focused on the critical role of water in immunity which is a new innovative concept. Until now there is no report available about the role of water in relation with immunity. Unfortunately water and its role in the cellular architecture and maintenance of immunity have superficially been studied. Water, to date, has merely been considered a solvent present in the cell. In fact life in all organisms (plants and animals) depends upon water. Water is the reality of immunity since it restores immune functions. An obsolete biased approach towards water and its role in reinstating immunity has been applied either because of lack of knowledge or prejudice in the realm of science that is not logically based [22].

Bio-energy water, introduced by Dae Myong Bio Company Limited Korea, is an innovatively upgraded drinking water which has health beneficial values, particularly those of immune recovering and immune activating in plants, human beings and animals equally. This water does not contain any additives and is obtained by natural energy (light/solar energy having a wavelength of $4 \sim 14 \mu \mathrm{m}$ ). This light energy (4 $14 \mu \mathrm{m})$ absorbs in the water that strengthens the natural hydrogen bonding in the water molecule, imparts long lasting biochemical and physiological effects in the cell by sustaining the original structure of biomolecules and their relative positioning in the tissues. This water is obtained by passing water through a patented purifying instrument created and developed by Dae Myong Bio Company Limited Korea.

In this study it was hypothesized that bioenergy water can heal degenerated adductor muscles of abalone. Therefore, the histopathological features of adductor muscles of abalone were investigated after rearing it in bio-energy water for four weeks 
so as to analyse the recovering effects of bioenergy water on the degenerated adductor muscles in abalone, Haliotis discus hannai.

\section{Materials and methods}

Both male and female abalones (Haliotis discus hannai) were fetched from different clinically healthy cemented tank culture farms in South Jeollanam-do Wando County, Republic of South Korea and were brought to Laboratory of Fish and Shellfish Pathology (LFSP) where they were kept in circular plastic water tanks. This study focused on investigating histological alteration in adductor muscles of juvenile abalone, Haliotis discus hannai, by using bio-energy water.

Abalones were divided into two groups, i.e. treatment and control groups. The same conditions for aeration, temperature, salinity, $\mathrm{pH}$ and dissolve oxygen were maintained during the experiment.

Control group was cultured in general water and the treatment group was cultured in bioenergy water. Both groups were kept under fasting condition during this experiment. Abalones were cultured in circular plastic water tank for four weeks. Five set of samples, in all, were collected from that of the total amount of abalones with $(n=8)$ abalones per sampling respectively.

The body weight, length, width, and height were measured by electronic scale and plastic ruler, and then dissected in the laboratory. Dissection was done with help of forceps and scissors. The abalone shell was removed out so that the abalone adductor muscle could appear clearly. The pictures were taken by using digital camera (Olympus E-P2-Japan). The adductor muscle was fixed in Bouin's solution. After 24 hours, those samples were cut in small pieces by sharp blade and put in labelled cassettes. All the labelled cassettes samples were re-fixed in $10 \%$ buffered formalin solution.

All the collected tissue samples were passed through a series of solvents for paraffin wax embedding (paraffin wax at $58-62{ }^{0} \mathrm{C}$ ). Tissues were washed and dehydrated through ethyl alcoholic grades $(70 \%, 80 \%, 90 \%$, $95 \%, 100 \%, 100 \%$, and $100 \%$ ). All samples were cleaned for 21 hours in xylene and 30 minutes before paraffin wax embedding.

The samples of adductor muscle were embedded with paraffin wax at 58-62 ${ }^{\circ} \mathrm{C}$. A part of embedded blocks of each tissue sample was sliced into $4 \mu \mathrm{m}$ sectioned ribbons using a rotary type microtome (Reichert - Jung 820, Leica, Germany). The sectioned ribbons were floated on the alcohol bath $(10 \%)$ and then in warm water bath at 50 ${ }^{0} \mathrm{C}$ to flatten out the sectioned ribbons. The sectioned ribbons were carefully collected on to a glass slide and were allowed to dry fully and flatten at $40{ }^{0} \mathrm{C}$ for 12 hours before proceeding to Hematoxylin and Eosin $(\mathrm{H} \&$ E) staining.

Hematoxylin and Eosin (H\&E) staining method was used to stain the tissue section. The stained samples were mounted with Canada Balsam for permanent preservation. Histological examination of different organ structures was done by taking photographs using light microscope (U-MDOB, Olympus optical Co. Ltd., Japan). Images of prepared slides of different organs were captured by using the DP2- BSW (Olympus, Japan) software.

Shell length, shell width, shell height, weight (total weight/shell weight) and shell weight in each group were measured. The ratios of shell width (\%), shell height (\%), shell weight $(\%)$ of the juvenile abalones in each group were calculated. Finally, the figures obtained were compared with shell length and the ratio of shell weight was compared with that of total weight. The adductor muscle was the most important among all the organs of abalones' histological assessment. In the assessment of adductor muscles, histological changes (swelling, vacuolization, atrophy, loss of muscular fibers) were examined. 
Moreover, their differentiation conditions were also studied.

\section{Results}

\section{First sampling (0 weeks)}

Abalones $(\mathrm{n}=8)$ were collected randomly. Shell length $(\mathrm{cm})$, shell width $(\mathrm{cm})$, shell height $(\mathrm{cm})$, shell weight $(\mathrm{g})$ and total weight (g) were measured during the dissection. Then the ratio of shell height to shell length, ratio of shell width to shell length, ratio of total weight to shell length and ratio of shell weight to total weight were calculated for control group as shown in (Table 1).

Adductor muscle around the muscle attachment portion was distorted, vitrified (hyalinization), vacuolized and the muscle castle was hollow and swollen because of vacuolization. Atrophic lesion in the adductor muscle was clearly observed in all 8 individuals. The Epilysium (Perimysium and muscle bundle) had free spaces that indicated declination in the muscle fiber diameter as shown in (Fig. 1).The same observations were made in the shell and adductor muscle attachment portions. Endomysium, surrounding the muscle, was observed in many cases which did not disappear. The remaining muscle fibres were displaying evident distortions of vacuolization.

\section{Experimental groups}

Juvenile abalones were cultured in bioenergy water for four weeks. Eight $(\mathrm{n}=8)$ individuals were randomly selected in each week. Shell length $(\mathrm{cm})$, shell width $(\mathrm{cm})$, shell height $(\mathrm{cm})$, shell weight $(\mathrm{g})$ and total weight $(\mathrm{g})$ of $(n=8)$ abalone were measured in all the experimental groups (i.e. second, third, fourth and fifth sampling respectively). Then the ratio of shell height to shell length, ratio of shell width to shell length, ratio of total weight to shell length and ratio of shell weight to total weight were calculated as shown in table 2, 3, 4 and 5 respectively. Histologically there were some clear differences in the muscle structure of the second sample, i.e., one week after application of bioenergy water than that of first sample before the application of bioenergy water. The muscle fiber histology showed improvement. The muscle fibers increased in density and grew thicker. A decrease in swelling and muscle fiber vacuolization was observed as shown in (Fig. 2).

Adductor muscle fiber histology showed remarkable improvement in the third sample, i.e., two weeks after application of bioenergy water as compared to that of first and second samples alike. Lesions, swelling of the adductor muscle, vitrification (hyalinization) and vacuolization of the muscles disappeared. The muscle fibers increased in density and grew thicker as shown in (Fig. 3). The muscle fiber recovery was observed in all the juvenile abalone cultured in bioenergy water.

Juvenile abalone cultured in bio-energy water group showed improvement in fourth sample, i.e., after three weeks. Shell mounting portion of the adductor muscle, vitrification (hyalinization), vacuoles in cytoplasm (vacuolization), atrophy and muscle fiber loss improved significantly. A clear improvement in the muscle density was observed. Swelling and vacuolization in the muscle fiber almost disappeared in most of the abalones as shown in (Fig 4).

Juvenile abalone cultured in bio-energy water group in fifth sample, i.e., after four weeks showed substantial improvement. Recovery in the histology of the muscle fibers and the muscular bundle was observed almost in all of the individuals of this sample. The improvements observed in the adductor muscle were much clearer in most of the cases. Muscle degeneration also disappeared in many of the cultured abalones as shown in (Fig 5). The area of muscle regeneration and improvement in adductor muscle in treatment groups was compared with that of control group in order to show the effects of 
bioenergy water in muscle regeneration as shown in (Fig. 6)

Table 1. Body weight and shell measurement of abalones in first sampling at 0 weeks ${ }^{1}$

\begin{tabular}{|c|c|}
\hline Measurement & Abalones in 0 weeks \\
\hline $\mathrm{SL}^{2}(\mathrm{~cm})$ & $5.86 \pm 0.38$ \\
\hline $\mathrm{Sw}^{3}(\mathrm{~cm})$ & $3.83 \pm 0.29$ \\
\hline $\mathrm{SH}^{4}(\mathrm{~cm})$ & $1.14 \pm 0.18$ \\
\hline Ratio of SH/SL (\%) & $19.4 \pm 0.1$ \\
\hline Ratio of SW/SL (\%) & $65.4 \pm 1.4$ \\
\hline $\mathrm{TW}^{5}(\mathrm{~g})$ & $26.77 \pm 2.16$ \\
\hline Ratio of TW/SL (\%) & $465.6 \pm 14.8$ \\
\hline $\mathrm{SW}^{6}(\mathrm{~g})$ & $5.13 \pm 0.72$ \\
\hline Ratio of SW/TW (\%) & $19.2 \pm 15.3$ \\
\hline
\end{tabular}

${ }^{1}$ Values are mean $\pm \mathrm{SD}(\mathrm{n}=8),{ }^{2} \mathrm{SL}=$ Shell Length, ${ }^{3} \mathrm{SW}=$ Shell Weight, ${ }^{4} \mathrm{SH}=$ Shell Height, ${ }^{5} \mathrm{TW}=$ Total Weight, ${ }^{6} \mathrm{SW}=$ Shell Weight

Table 2. Body weight and shell measurement of abalones in second sample at 1 weeks 1

\begin{tabular}{|c|c|c|}
\hline Measurement & Abalones in general Water & Abalone in Bio-energy water \\
\hline $\mathrm{SL}^{2}(\mathrm{~cm})$ & $5.86 \pm 0.38$ & $4.83 \pm 0.08$ \\
\hline $\mathrm{SW}^{3}(\mathrm{~cm})$ & $3.83 \pm 0.29$ & $3.32 \pm 0.10$ \\
\hline $\mathrm{SH}^{4}(\mathrm{~cm})$ & $1.14 \pm 0.18$ & $0.93 \pm 0.08$ \\
\hline Ratio of SH/SL (\%) & $19.4 \pm 0.1$ & $19.3 \pm 1.7$ \\
\hline Ratio of SW/SL (\%) & $65.4 \pm 1.4$ & $68.4 \pm 1.2$ \\
\hline TW $(\mathrm{g})$ & $26.77 \pm 2.16$ & $60.75 \pm 5.09$ \\
\hline Ratio of TW/SL (\%) & $456.6 \pm 14.8$ & $1272.5 \pm 40.1$ \\
\hline $\mathrm{SW}^{6}(\mathrm{~g})$ & $5.13 \pm 0.72$ & $15.91 \pm 1.91$ \\
\hline Ratio of SW/TW (\%) & $19.2 \pm 15.3$ & $25.9 \pm 7.8$ \\
\hline
\end{tabular}

${ }^{1}$ Values are mean $\pm \mathrm{SD}(\mathrm{n}=8),{ }^{2} \mathrm{SL}=$ Shell Length, ${ }^{3} \mathrm{SW}=$ Shell Weight, ${ }^{4} \mathrm{SH}=$ Shell Height, ${ }^{5} \mathrm{TW}=$ Total Weight, ${ }^{6} \mathrm{SW}=$ Shell Weight

Table 3. Body weight and shell measurement of abalones in third sample at 2 weeks ${ }^{1}$

\begin{tabular}{|c|c|c|}
\hline Measurement & Abalones in general Water & Abalone in Bio-energy water \\
\hline $\mathrm{SL}^{2}(\mathrm{~cm})$ & $5.84 \pm 0.38$ & $4.82 \pm 0.13$ \\
\hline $\mathrm{SW}^{3}(\mathrm{~cm})$ & $3.84 \pm 0.29$ & $3.35 \pm 0.22$ \\
\hline $\mathrm{SH}^{4}(\mathrm{~cm})$ & $1.14 \pm 0.18$ & $0.94 \pm 0.10$ \\
\hline Ratio of SH/SL $(\%)$ & $19.4 \pm 0.1$ & $19.5 \pm 2.7$ \\
\hline Ratio of SW/SL(\%) & $65.4 \pm 1.4$ & $69.4 \pm 1.3$ \\
\hline $\mathrm{TW}^{5}(\mathrm{~g})$ & $26.77 \pm 2.16$ & $16.23 \pm 2.69$ \\
\hline Ratio of TW/SL $(\%)$ & $456.6 \pm 14.8$ & $69.2 \pm 32.3$ \\
\hline $\mathrm{SW}^{6}(\mathrm{~g})$ & $5.13 \pm 0.72$ & $3.33 \pm 0.28$ \\
\hline Ratio of SW/TW $(\%)$ & $19.2 \pm 15.3$ & $20.6 \pm 9.2$ \\
\hline
\end{tabular}

${ }^{1}$ Values are mean $\pm \mathrm{SD}(\mathrm{n}=8),{ }^{2} \mathrm{SL}=$ Shell Length, ${ }^{3} \mathrm{SW}=$ Shell Weight, ${ }^{4} \mathrm{SH}=$ Shell Height, ${ }^{5} \mathrm{TW}=$ Total Weight, ${ }^{6} \mathrm{SW}=$ Shell Weight 
Table 4. Body weight and shell measurement of abalones in fourth sample at 3 weeks ${ }^{1}$

\begin{tabular}{|c|c|c|}
\hline Measurement & Abalones in general water & Abalone in bio-energy water \\
\hline $\mathrm{SL}^{2}(\mathrm{~cm})$ & $5.86 \pm 0.38$ & $5.06 \pm 0.34$ \\
\hline $\mathrm{SW}^{3}(\mathrm{~cm})$ & $3.83 \pm 0.29$ & $3.85 \pm 0.56$ \\
\hline $\mathrm{SH}^{4}(\mathrm{~cm})$ & $1.14 \pm 0.18$ & $1.15 \pm 0.20$ \\
\hline Ratio of SH/SL $(\%)$ & $19.4 \pm 0.14$ & $22.8 \pm 2.7$ \\
\hline Ratio of SW/SL (\%) & $65.4 \pm 1.4$ & $76.2 \pm 10.2$ \\
\hline $\mathrm{TW}^{5}(\mathrm{~g})$ & $26.77 \pm 2.16$ & $66.68 \pm 11.51$ \\
\hline Ratio of TW/SL (\%) & $456.6 \pm 14.8$ & $1316.6 \pm 43.7$ \\
\hline $\mathrm{SW}^{6}(\mathrm{~g})$ & $5.13 \pm 0.72$ & $18.32 \pm 1.90$ \\
\hline Ratio of SW/TW $(\%)$ & $19.2 \pm 15.3$ & $27.5 \pm 34.2$ \\
\hline
\end{tabular}

${ }^{1}$ Values are mean $\pm \mathrm{SD}(\mathrm{n}=8),{ }^{2} \mathrm{SL}=$ Shell Length, ${ }^{3} \mathrm{SW}=$ Shell Weight, ${ }^{4} \mathrm{SH}=$ Shell Height, ${ }^{5} \mathrm{TW}=$ Total Weight, ${ }^{6} \mathrm{SW}=$ Shell Weight

Table 5. Body weight and shell measurement of abalones in fifth sample at 4 weeks ${ }^{1}$

\begin{tabular}{|c|c|c|}
\hline Measurement & Abalones in general water & Abalone in bio-energy water \\
\hline $\mathrm{SL}^{2}(\mathrm{~cm})$ & $5.85 \pm 0.38$ & $4.93 \pm 0.40$ \\
\hline $\mathrm{SW}^{3}(\mathrm{~cm})$ & $3.84 \pm 0.29$ & $3.38 \pm 0.23$ \\
\hline $\mathrm{SH}^{4}(\mathrm{~cm})$ & $1.15 \pm 0.18$ & $0.98 \pm 0.12$ \\
\hline Ratio of SH/SL (\%) & $19.4 \pm 0.1$ & $20.2 \pm 2.8$ \\
\hline Ratio of SW/SL (\%) & $65.4 \pm 1.4$ & $68.6 \pm 1.7$ \\
\hline $\mathrm{TW}^{5}(\mathrm{~g})$ & $26.77 \pm 2.16$ & $61.31 \pm 9.42$ \\
\hline Ratio of TW/SL (\%) & $456.6 \pm 14.8$ & $1241.4 \pm 42.7$ \\
\hline $\mathrm{SW}^{6}(\mathrm{~g})$ & $5.14 \pm 0.72$ & $16.84 \pm 3.02$ \\
\hline Ratio of SW/TW $(\%)$ & $19.2 \pm 15.3$ & $27.4 \pm 31.4$ \\
\hline
\end{tabular}

${ }^{1}$ Values are mean $\pm \mathrm{SD}(\mathrm{n}=8),{ }^{2} \mathrm{SL}=$ Shell Length, ${ }^{3} \mathrm{SW}=$ Shell Weight, ${ }^{4} \mathrm{SH}=$ Shell Height, ${ }^{5} \mathrm{TW}=$ Total Weight, ${ }^{6} \mathrm{SW}=$ Shell Weight

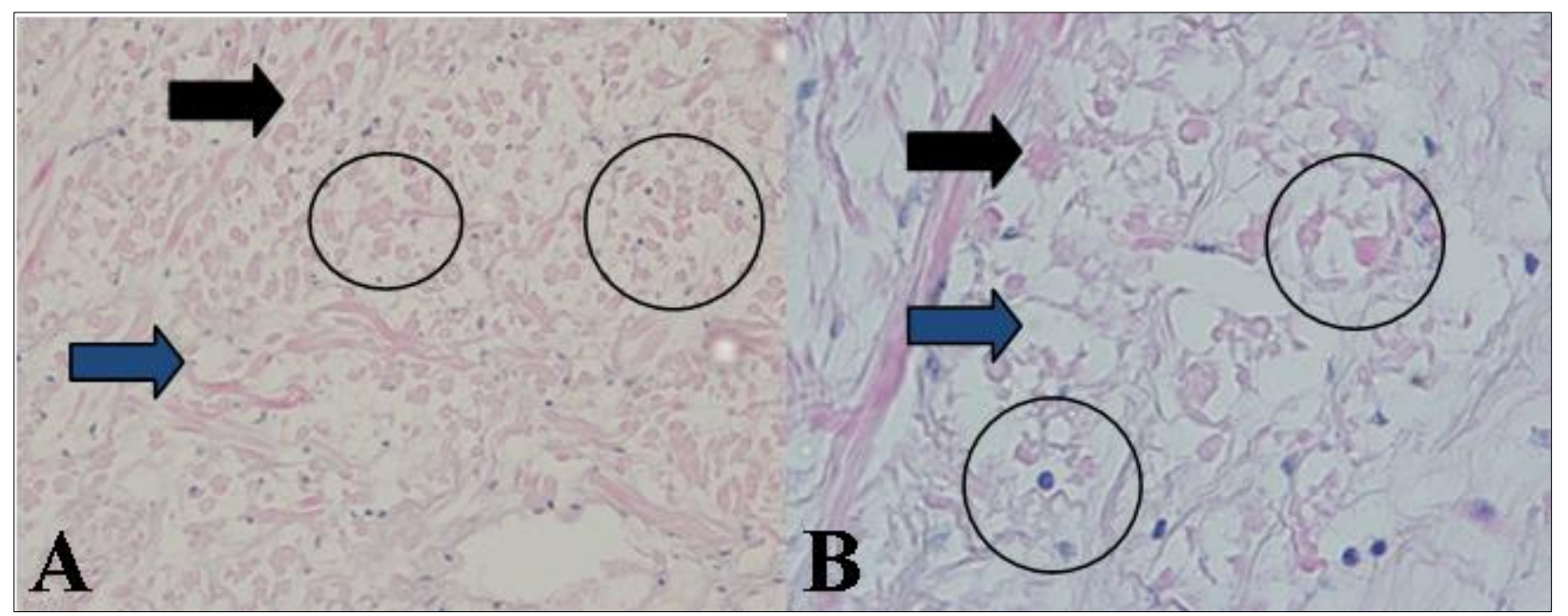

Figure 1. Adductor muscle tissues in control group, before applying bio-energy water (A: X400 B: X1000.H\&E $50 \mu \mathrm{m})$.Cellular swelling in adductor muscle fibrils, muscle vacuolization of the adductor muscle fibres (arrows). Cellular atrophy, degenerative muscle fibrils, myonecrosis (elliptical circles) in muscle fibres and loss of muscle fibres in adductor muscle are shown in figure 


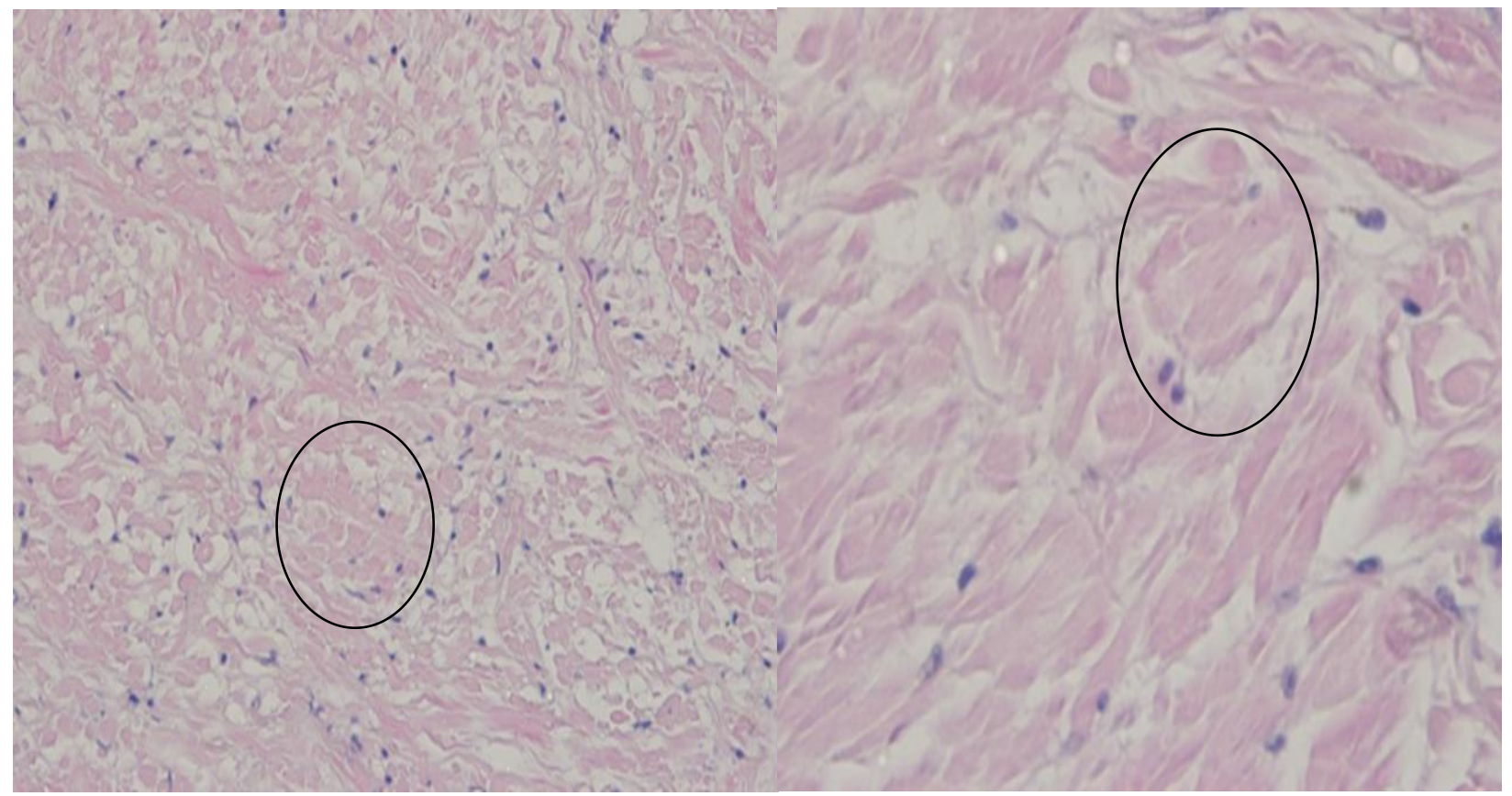

Figure 2. Adductor muscle of abalone in bio-energy water after one week. Vacuolization and swelling gradually decreased and improvement in adductor muscle histology (elliptical circle) is shown ( $\mathrm{X} 400$ and $\left.\mathrm{X} 1000 . \mathrm{H} \& \mathrm{E} \_50 \mu \mathrm{m}\right)$



Figure 3. Adductor muscle of abalone in bio-energy water after two weeks. Lesions, swelling of the adductor muscle, vitrification (hyalinization) gradually decreased and improvement in adductor muscle histology (elliptical circle) is shown (X400 and X1000.H\&E $\left.\_50 \mu \mathrm{m}\right)$ 


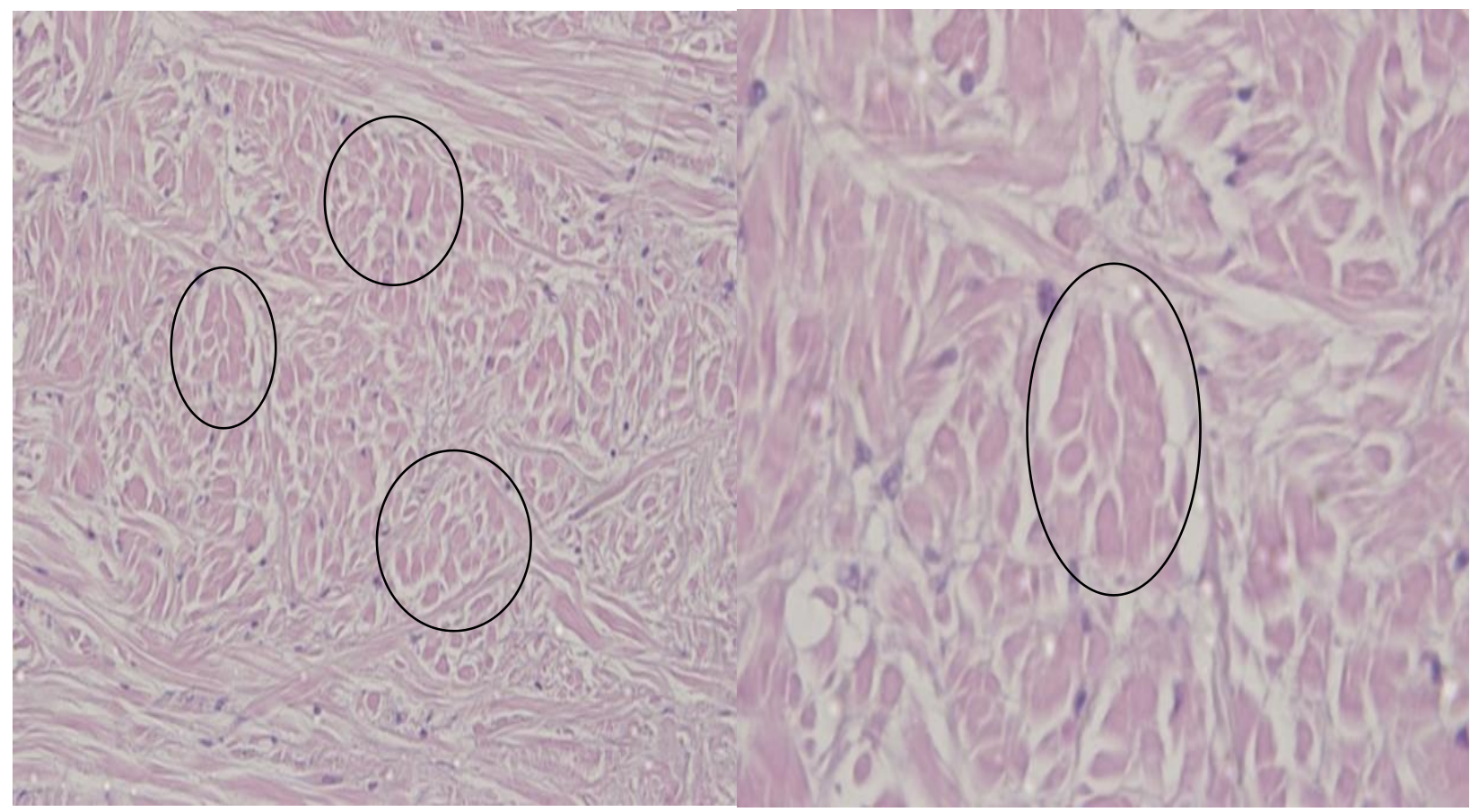

Figure 4. Adductor muscle of abalone in bio-energy water after three weeks. Swelling, vacuolization in the muscle fiber almost disappeared. Shell mounting portion of the adductor muscle, vitrification (hyalinization), vacuoles in cytoplasm, atrophy and muscle fiber loss improved significantly (elliptical circle) is shown (X400 and X1000.H\&E _ $50 \mu \mathrm{m})$

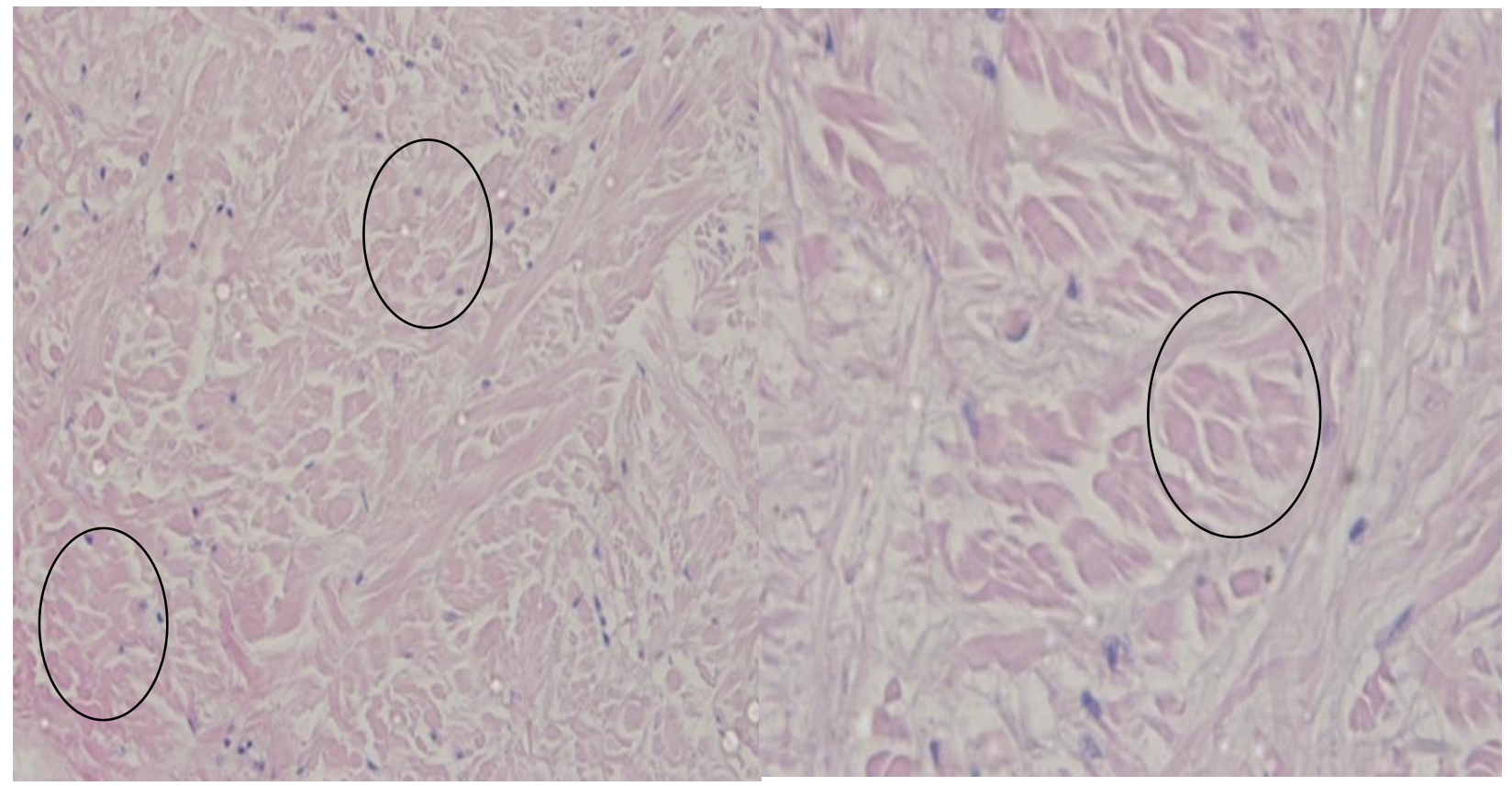

Figure 5. Adductor muscle of abalone in bio-energy water after four weeks. The muscle fibers and the muscular bundle recovered. Increase in muscle fiber diameter, no vacuolization, swelling and complete muscle fibers recovery (elliptical circle) is shown (X400 and X1000. H\&E _ $50 \mu \mathrm{m})$ 


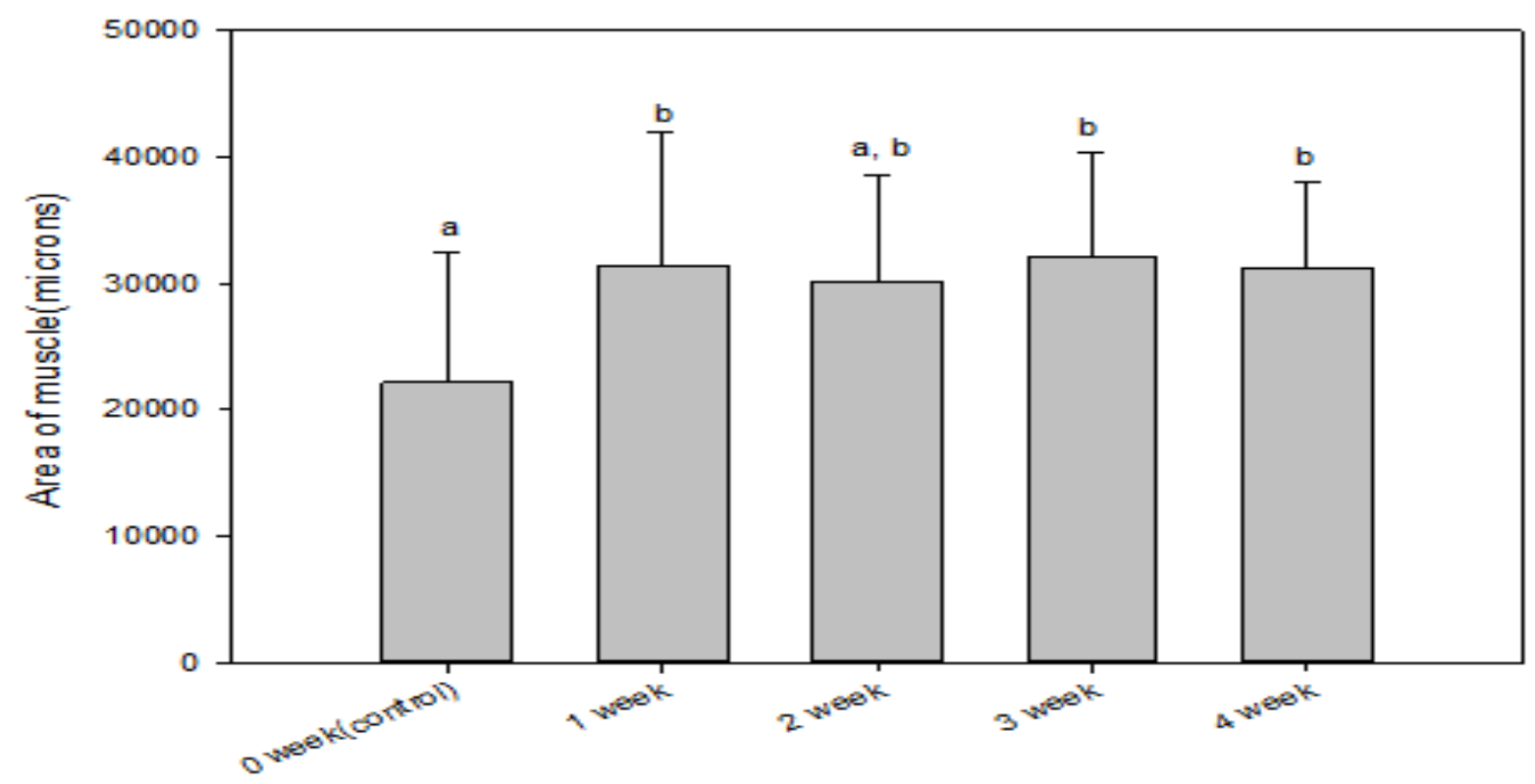

Period of bioenergy water exposure

Figure 6. Adductor muscle recovery in juvenile abalone in control group (general water, 0 weeks) compared with that of treatment groups (bio-energy water, 1-4 weeks).The area of muscle in adductor muscle was calculated with 400 magnification photograph

\section{Discussion}

The prime objective of this study was to assess the recovering effects of bio-energy water on the lesion found in the degenerated adductor muscles of juvenile abalone (Haliotis disucs hannai). Bio-energy water, used in this study, was provided by Dae Myong Bio Company Limited, Republic of Korea. The adductor muscle lesions of abalone, cultured in bio-energy water, were examined under light microscope in order to assess the recovering process of adductor muscle after being cultured in bioenergy water.

The results were remarkably positive. Abalone in the first sample (before the application of bioenergy water) exhibited complete muscular degeneration. Lesion was found distributed in the portion of adductor muscles which is normally attached to the outer shell area of the animal body. Muscle fiber degeneration, vacuolization, hyalinization and muscle swelling were caused by necrosis. In the second sample (1 week after the application of bioenergy water) there was a great improvement in the adductor muscle histology. In the third sample (2 weeks after the application of bioenergy water) muscle fibers increased in density and started to grow thicker after being cultured in bioenergy water with complete recovery in almost all individuals. In fourth sample (3 weeks after the application of bioenergy water) lesion, swelling of the adductor muscle, vitrification (hyalinization) and vacuolization of the muscles disappeared gradually with a clear improvement in muscle fiber histology in most of the abalones. In fifth and final sample (4 weeks after the application of bioenergy water), 
shell mounting portion of the adductor muscle fiber improved significantly. Vitrification (hyalinization), vacuoles in cytoplasm (vacuolization), cellular atrophy reduced and muscle fibrils grew thicker in diameter. No swelling and vacuolization in the muscle fiber in most of the individuals was observed. These all changes occurred because of bioenergy water and its efficacy in muscle lesion recovery.

Adductor muscle fibrils did not recover in any of the juvenile abalones cultured in bioenergy water for three months in excessive feeding condition. This might have been because of free radicals and Super Oxide Dismutase (SOD) produced due to excessive feeding [22]. Not much work, except a few, has so far been done on the immunopotentiating characteristics and adductor muscle repairing properties of bioenergy water in aquaculture sector. Adductor muscle fibrils in adult abalones recovered in the third week after being cultured in bioenergy water for two months in fasting condition [23]. Therefore, the present study was conducted on juvenile abalone cultured in bioenergy water in fasting condition so as to avoid any negative effects of overfeeding, free radicals, food toxicants etc., on the structural changes of adductor muscles after being cultured in bioenergy water.

Adductor muscle is an important organ of the abalone body as it is attached with the shell of the animal body. It maintains the balance and movement of the whole of abalone body. It also helps abalone attach to the substratum [24]. Muscle degeneration in abalone because of high temperature causes mass mortality. Any problems in the adductor muscles (lesion, necrosis) cause the detachment of adductor muscle from the main shell that leads to death, but the real mechanism of complete degeneration of adductor muscles has so far not been understood [ 25-27]. Some studies have also reported that SOD (Super Oxide Sismutase), hydrogen peroxide $\left(\mathrm{H}_{2} \mathrm{O}_{2}\right)$, oxidative stress, accumulation of toxic ammonia may also cause muscle degeneration in abalones primarily in culture farms where abalones are fed with excessive food for the purpose of their fast growth. Over feeding produces the aforementioned lethal toxicants injurious to life of abalones [28, 29].

Bio-energy water is devoid of any chemical additives. It is obtained by passing solar energy (life-giving energy having 4-14 $\mu \mathrm{m}$ wave length) through common water. It also ensures maximum absorbance and bioavailability of water molecule in the body. The results of this study proved the efficacy of bioenergy water. Degenerated adductor muscles showed remarkable recovery in juvenile abalone reared in bioenergy water for four weeks. The results obtained in this study (under fasting condition) are similar to the results reported in case of adult abalone cultured in bioenergy water (under fasting condition for three months.

Water is the reality of immunity. Immunity, which is the power of a living organism to remain alive, is based on the structurefunction relationship. Any disturbance in the structure perturbs function or immunity. This maintenance of normal structure -function relationship (immunity) in the living organisms is sustained by water. Thus, it can be said that water (hydrogen bond) is the life giving medium in the living cells.

This innovative idea regarding the role of water in strengthening immune power has still not been known because of prejudice about the role of water. It is high time we understood logically the real role of water, i.e., immune strengthening medium, in the living cells and spread this concept across the world.

The results of this study recommend that water, the most studied liquid on earth, should no more be underestimated. The recovery of degenerated muscles of juvenile 
abalone was only possible because of the unique characteristics of water molecule which retained the original position of muscle fibers, cells and tissues that indicated the life giving property of water molecule. Water quality parameters, environmental pollution, toxicants and pathongs have only been held responsible for mass mortality in abalones. This study does not deny the aforesaid causes of mortality in abalone, but simultaneously suggests that the real role of water should also not be neglected altogether.

\section{Conclusion}

Keeping in view the health enhancing properties of bioenergy water, it is suggested that bioenergy water can be used for the health improvement purposes in aquaculture sector, since water is the backbone of immunity and essence of structure-function reinstatement in the living organisms. Positive results regarding the application of bioenergy water in agriculture and livestock sectors have already been reported in Republic of Korea and Vietnam. Therefore, it is recommended that both fish and shell fish be cultured in bio-energy water with moderate feeding as overfeeding is injurious to fish and shell fish health. This would be cost effective and it would also minimize the risks of lethal diseases mainly caused by food toxicants in aquaculture industry.

\section{Authors' contributions}

Conceived and designed the experiments: AU Shah \& HM Do, Performed the experiments: AU Shah, Analysed the data: LK Baloch, Contributed materials/ analysis/ tools: BS Kim, Wrote the paper: AU Shah.

\section{Acknowledgement}

Firstly, I would like to express my special thanks and gratitude to the government of Republic of South Korea and the Korea International Cooperation Agency (KOICA) for sponsoring this research work at Pukyong National University (PKNU) Pusan, Republic of South Korea.
I would like to extend my sincere thanks to Professor Min Do Huh as this work would not have been possible without his kind assistance and guidance.

I am highly indebted to Kim Bo Sung, my laboratory captain, who guided me in every step of this work. My thanks and appreciations also go to Lawang Khan Baloch, Gyoungsik Kang, Chunyoung, Hanji, Lawang Khan Baloch and all other laboratory mates who encouraged and supported me during my work. I would also like to thank Professor Sungchul Charles Bai and Professor Shin Hyeon-Ok for correcting the mistakes in my research work. Furthermore, I would also like to acknowledge the crucial role of KOICA programme coordinator Professor Doctor Kyoungmi Kang, KOICA course coordinator Miss Kim Seulki and their assistants Miss Miran Huang and Miss Yurim Song for their unending support during this research work at PKNU.

\section{Reference}

1. Cox KW (1962). California abalones, family Haliotidae (No. 118). Department of Fish and Game, the Resources Agency, State of California.

2. Clark SA, Miller AC \& Ponder WF (2003). Revision of the snail genus Austropyrgus

(Gastropoda: Hydrobiidae): a morphostatic radiation of freshwater gastropods in Southeastern Australia (Vol 28). Australian Museum.

3. Gorfine HK (2002). Assessment of the sustainability of Victorian abalone resources (Doctoral dissertation).

4. Geiger DL (1999). Distribution and biogeography of the recent Haliotidae world-wide. (Gastropoda: Vetigastropoda). Bollettino Malacol (35): 57-118.

5. Rhode C (2013). Signatures of selection in natural and cultured abalone (Haliotis midae): a population genomics 
study (Doctoral dissertation, Stellenbosch: Stellenbosch University).

6. Hahn KO (1989). Survey of the commercially important abalone species in the world. Handbook of culture of abalone and other marine gastropods. CRC Press, Boca Raton, pp 3-11.

7. Hakin FAO (1990). Training Course on Artificial Breeding of Abalone, Haliotis discus hannai, in Korea DPR. Training Manual on Abalone culture in Korea. Demonstration Project (RAS/90/002).

8. Leighton $\mathrm{P} \&$ Robinson $\mathrm{G}$ (2008). Abalone hatchery manual. Bord Iascaigh Mhara, Aquaculture Technical Section, Aquaculture Development Division.

9. Thearith THE (2015). The histological effects of bio-energy water on degenerated adductor muscle found endemically in culture adult abalone, Haliotis discus hannai, in feeding condition. (MS dissertation).

10. Mann R (1993). Abalone of the world: Biology, fisheries and culture: SA Shepherd, MJ Tegner and SA Guzman del Proo (Editors), Fishing News Books, Blackwell Scientific Publications Ltd., 603 pp. ISBN 0-85238-181-6, Price UK£ 65.00.

11. Hakin FAO (1990). Training Course on Artificial Breeding of Abalone, Haliotis discus hannai, in Korea DPR. Training Manual on Abalone culture in Korea. Demonstration Project (RAS/90/002).

12. Fisher WS \& Newell RI (1986). Salinity effects on the activity of granular haemocytes of American oysters, Crassostrea virginica. The Biol Bulletin 170(1): 122-134.

13. Dang VT, Speck P \& Benkendorff K (2012). Influence of elevated temperatures on the immune response of abalone, Haliotis rubra. Fish \& Shellfish Immunol 32(5): 732-740.
14. Hooper C, Day R, Slocombe R, Handlinger J \& Benkendorff K (2007). Stress and immune responses in abalone: limitations in current knowledge and investigative methods based on other models. Fish \& Shellfish Immunol 22(4): 363-379.

15. Harris JO, Maguire GB, Edwards SJ \& Johns DR (1999). Low dissolved oxygen reduces growth rate and oxygen consumption rate of juvenile greenlip abalone, Haliotis laevigata Donovan. Aquacul 174(3-4): 265-278.

16. Shumway SE (1977). Effect of salinity fluctuation on the osmotic pressure and $\mathrm{Na}+, \mathrm{Ca} 2+$ and $\mathrm{Mg} 2+$ ion concentrations in the hemolymph of bivalve molluscs. Marine Biol 41(2): 153-177.

17. Huchette SM, Koh CS \& Day RW (2003). Growth of juvenile blacklip abalone (Haliotis rubra) in aquaculture tanks: effects of density and ammonia. Aquacul 219(1-4): 457-470.

18. Mgaya YD \& Mercer JP (1995). The effects of size grading and stocking density on growth performance of juvenile abalone, Haliotis tuberculata Linnaeus. Aquacul 136(3-4): 297-312.

19. Trueman ER \& Brown AC (1985). The mechanism of shell elevation in Haliotis (Mollusca: Gastropoda) and a consideration of the evolution of the hydrostatic skeleton in Mollusca. $J$ of Zool 205(4): 585-594.

20. Frescura M (1990). Aspects of the structure and function of some gastropod columellar muscles (Mollusca) (Doctoral dissertation, Rhodes University).

21. Krecar IM, Kolega M \& Kunac SF (2014). The effects of drinking water on attention. Procedia-Social and Behavioral Sci 159: 577-583.

22. Davidson R, Lauritzen A \& Seneff S (2013). Biological water dynamics and 
entropy: a biophysical origin of cancer and other diseases. Entropy 15(9): 38223876.

23. Chankakada Mak CKD (2017). The histological effects of bio-energy water on degenerated adductor muscle of juvenile abalone, Haliotis discus hannai, in feeding condition. MS. Thesis. Department of Aquatic life Medicine, Pukyong National University, Busan, South Korea.

24. Thearith THE (2015). The histological effects of bio-energy water on degenerated adductor muscle found endemically in culture adult abalone, Haliotis discus hannai, in feeding condition. M.S. Thesis. Department of Aquatic life Medicine, Pukyong National University, Busan, South Korea.

25. Fretter V \& Graham A (1962). British prosobranch molluscs. Their functional anatomy and ecology. British prosobranch molluscs. Their Functional Anatomy and Ecol.

26. Kim BS, Yi SJ, Hwang SM, Lee MK, Park YJ, Song KJ \& Huh MD (2014). Myopathy in clinically healthy cultured abalone Haliotis discus hannai. Korean J of Fisheries and Aquatic Sci 47(2): 174178.

27. Dang VT, Speck P \& Benkendorff K (2012). Influence of elevated temperatures on the immune response of abalone, Haliotis rubra. Fish \& Shellfish Immunol 32(5): 732-740.

28. Kim TH, Yang MH, Choe MK, Han SJ \& Yeo IK (2005). Physiological studies on acute water-temperature stress of juvenile abalone, Haliotis discus hannai. J of Aquacul 18(1): 7-12.

29. Liu Z, Zhou T, Ziegler AC, Dimitrion $P$ \& Zuo L (2017). Oxidative stress in neurodegenerative diseases: from molecular mechanisms to clinical applications. Oxidative Medicine and Cellular Longevity. 